\title{
DESIGN FIBER TO THE HOME GIGABIT PASSIVE OPTICAL NETWORK UDAYANA UNIVERSITY, SUDIRMAN CAMPUS
}

\author{
Sudiarta Pande Ketut ${ }^{1}$, Alit Swamardika I B ${ }^{2}$, Gunantara Nyoman ${ }^{3}$ \\ ${ }^{1,2,3}$ Department of of electrical Engineering, Faculty of Engineering, \\ Udayana University, Bukit Jimbaran \\ Bali, Indonesia \\ sudiarta@unud.ac.id
}

\begin{abstract}
To find out the need for fiber optic access network devices from NOC to rooms at Udayana University, Sudirman Campus, fiber to the home network design was made with Gigabit Passive Optical Network (GPON) technology. Selection of GPON technology to reduce the number of ports on OLT and the number of fiber cores compared to the existing technology using point to point. Assuming the bitrate in each room is $21 \mathrm{Mbps}$ and 291 rooms to be served, it takes 5 OLT ports on the NOC. Feeder Cable Network consists of 5 cores distributed to each location using 3 units of 1: 4 splitter, 4 units of 1: 8 splitter, 6 units of 1:16 splitter, 1:32 splitter of 6 units. To maintain service quality, 16 amplifiers are needed. The required fiber cable length is $2.5 \mathrm{~km}$. The quality of service is tested using the Optisystem simulator. The result is that at the closest distance the PRx value is -14.059 $\mathrm{dBm}$, with BER 6.13608 e-103, Q Factor 21.511. Meanwhile, at the farthest distance, the PRx value is $-14.105 \mathrm{dBm}$, with BER of 1.52751 e-120, and Q Factor 23.3159. The results obtained still meet the ITU-T G.984.2 standard.
\end{abstract}

Index Terms- GPON, FTTH, Optical Fiber, OLT.

\section{INTRODUCTION}

The telecommunications sphere has matured to the point that operators are looking to offer network convergence and enable a revolution in consumer media device interaction. This demand is met by deeper penetration of optical fiber in access networks and increased fiber-to-home deployment (FTTH) [1]. Requirements such as high bandwidth and capacity for internet speed, High Definition Television "HDTV" and Voice Over Internet Protocol "VOIP", led to the proposal for a Fiber To Home FTTH Access Network. FTTH based on Giga Passive Optical Network (GPON) technology is one technique that can provide triple play services at a reasonable cost. It only uses passive equipment except at the head office and customer premises [2]. Comparison of conventional optical technology compared to GPON technology shows that GPON provides more advantages [3]. It is necessary to introduce the implementation of GPON in campus networks, and the difference with traditional campus networks [4]. Can be used as a reference for implementing GPON on campus is the interconnection design between the three campuses of Shenzhen University [5]. One of the locations of the Udayana University Campus which is located on the Sudirman Campus with a Clear Channel Design has been designed since 2006 and now the development of the new building has increased significantly. The design of the FTTH network uses GPON technology by looking at the parameters of the power link budget and the resulting attenuation [6]. ITU-T G.984 is a Gigabit Passive Optical Network (GPON) capable standard. In this paper, a $2.5 \mathrm{~Gb} / \mathrm{s}$ GPON link is presented. The quality or performance of a digital communication system is determined by the value of BER or $\mathrm{Q}$ with respect to other parameters such as receiver sensitivity [7]. Gigabit-capable Passive Optical Network (PON) systems, such as GPON (standardized in the ITU-T Rec. G.984) and 1G-EPON series have been standardized and are now being mass-deployed in various markets around the world [7]. A brief study of the GPON standard based on the ITU (International Telecommunications Union) standard G.984.X was included, thus governing the network and its characteristics [8]. Fiber Optic network design simulation using GPON technology can be done using the Optisystem application [9].

\section{MeTHOD}

The method used in designing the data network at Udayana University, Sudirman Campus is FTTH with GPON technology in the journal "GPON in 
Telecommunication Network" Obtained the result that GPON is a more efficient New Generation Network technology[10].

The GPON network topology in the design is shown in Figure 1.

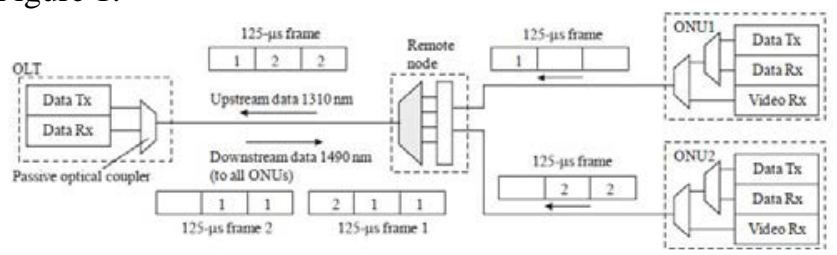

Figure 1 GPON network topology in design 1 [10]

The design begins with a survey of the number of spaces and buildings in the Sudirman campus. To determine the length of the path of the fiber optic line is assisted by GPS. From the survey data, the amount of OLT needed will be calculated with the assumption that the bandwidth in each room is 21 Mbps, consisting of 15 Mbps for data needs, 5 Mbps Remote learning, 1 Mbps File Exchange. From the results of the space survey and the bandwidth assumption in each room, it will be obtained how much OLT is needed, including the distribution network equipment requirements. The initial steps describe networking on the Optysystem. Each feeder cable will be analyzed at the ONU regarding the quality of the Optical Fiber network at the closest and farthest points, respectively including signal level, BER, Eye Pattern based on ITU-T G.984.2 standard [11].

Table 1 shows the fiber optic network speed assumptions in each room.

Table I

Service Bit Rate that will be broadcast on the Sudirman Campus FFTH network

\begin{tabular}{|l|l|}
\hline \multicolumn{1}{|c|}{ Service } & \multicolumn{1}{c|}{ Bit Rate } \\
\hline Data & $15 \mathrm{Mbps}$ \\
\hline Remote Learning & $5 \mathrm{Mbps}$ \\
\hline File Exchange & $1 \mathrm{Mbps}$ \\
\hline Total Bit Rate & $\underline{21 \mathrm{Mbps}}$ \\
\hline
\end{tabular}

Table 2 shows the standards used according to the ITU-T G984.2 Standard

Table II

Spesifikasi Standar FTTH oleh ITU-T G 984.2 [11]

\begin{tabular}{|l|l|}
\hline Name & Value \\
\hline Tx Optical Power & $1.5 \mathrm{~s} / \mathrm{d} 5 \mathrm{dBm}$ \\
\hline Rx Loss & $-8 \mathrm{~s} / \mathrm{d}-27 \mathrm{~dB}$ \\
\hline Fiber loss & $0.2 \mathrm{~dB} / \mathrm{km}$ \\
\hline Splitter Loss 1:2 & $3 \mathrm{~dB}$ \\
\hline Splitter Loss 1:4 & $8 \mathrm{~dB}$ \\
\hline Splitter Loss 1:4 & $10 \mathrm{~dB}$ \\
\hline Splitter Loss 1:16 & $12 \mathrm{~dB}$ \\
\hline Splitter Loss 1:32 & $15 \mathrm{~dB}$ \\
\hline Splitter Loss 1:64 & $18 \mathrm{~dB}$ \\
\hline Connector Loss & $0.2 \mathrm{~dB}$ \\
\hline Wavelength & $1550 \mathrm{~nm}$ \\
\hline Max. Physical Distance & $20 \mathrm{~km}$ \\
\hline Split Ratio & $\mathrm{s} / \mathrm{d} 64$ \\
\hline Nominal Bit Rate Downstream & 1250 atau 2500 Mbps \\
\hline
\end{tabular}

\section{RESULT}

The location of the ODC and ODP survey results is mapped with the help of the Google Earth application including measuring the distance from each location point as shown in Figure 2. From the data obtained on google earth, followed by simulating in Optisystem Software, there are 5 feeder cables to each distribution

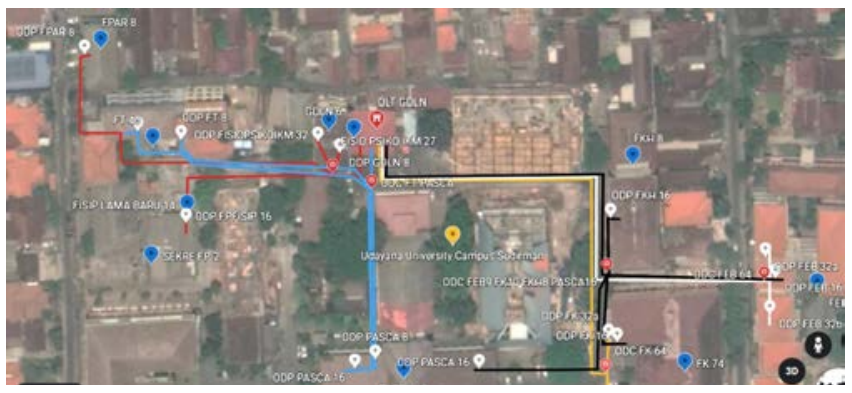

Fig. 2 Optical Fiber Distribution Map and ODC and ODP Location Points

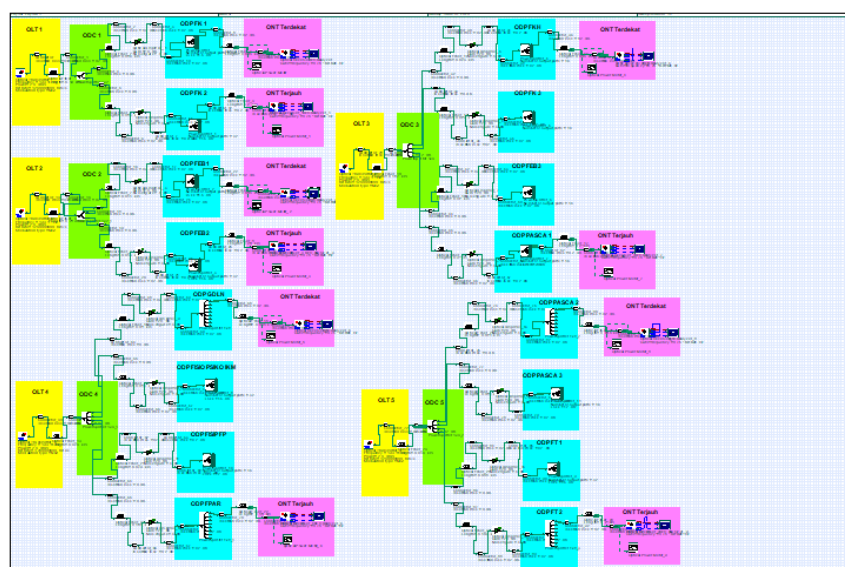

Fig. 3 Simulation of the GPON network of Udayana University, Sudirman Campus

Of the five feeder cables in the planning, Figure 4 shows the test on the OLT 1 line which includes the FK building.

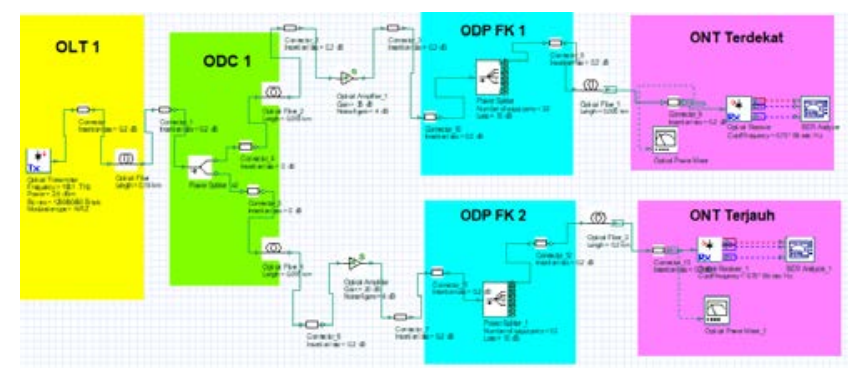

Fig. 4 FTTH design in OLT 1

Of the five feeder cables in the planning, Figure 4 shows the test on the OLT 1 line which includes the FK building. Results of Measurement of the Quality of Signal Power Received at the Nearest ONT OLT 1 a. The Power Measurement results at the ONT are shown in figure 5 


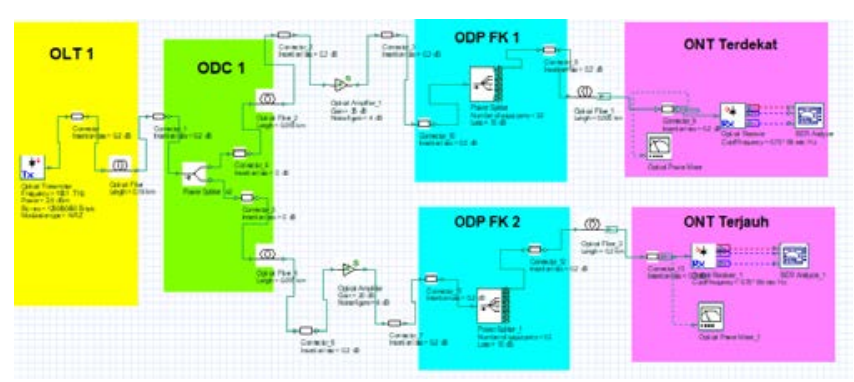

Fig. 4 FTTH design in OLT 1

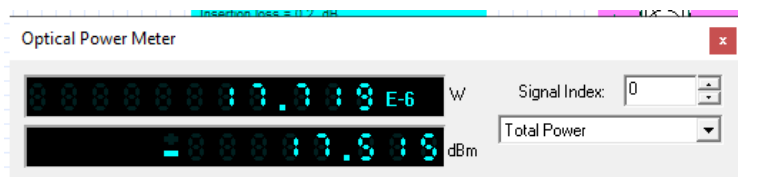

Fig. 5 Power Measurement in the nearest ONT device on the OLT 1 feeder

The measurement results for BER, Q-Factor and Eye Diagram Pattern are shown in Figure 6

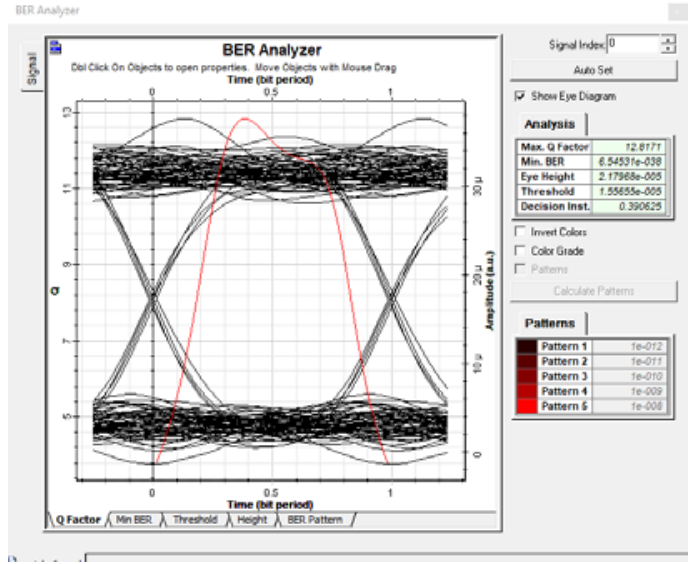

Fig. 6 The measurement results of BER on the closest ONT to the OLT 1 feeder

The quality of the FTTH network with GPON from the measurement results on the simulator including PRx ONT, BER, and Q-Factor is shown in Table 3.

Table III

PRx ONT, ber, and, Q-factor values

\begin{tabular}{|c|c|c|c|c|c|}
\hline No & OLT & Nama ODP & PRx (dBm) & BER & Q-Factor \\
\hline \multirow{2}{*}{1} & \multirow{2}{*}{ OLT 1 } & ODP FK 1 & -17.515 & 6.54 e-038 & 12.8171 \\
\cline { 3 - 6 } & & ODP FK 2 & -17.555 & 3.76 e-029 & 11.1447 \\
\hline 2 & \multirow{2}{*}{ OLT 2 } & ODP FEB 1 & -17.520 & 2.11 e-030 & 11.3988 \\
\cline { 3 - 6 } & & ODP FEB 2 & -17.570 & 2.59 e-026 & 10.5475 \\
\hline 3 & \multirow{2}{*}{ OLT 3 } & ODP FKH & -19.084 & 5.78 e-013 & 7.11031 \\
\cline { 3 - 6 } & & PASCA 1 & -19.239 & 4.57 e-012 & 6.81935 \\
\hline 4 & \multirow{2}{*}{ OLT 4 } & ODP GDLN & -14.050 & 1.98 e-103 & 21.5631 \\
\cline { 3 - 6 } & & ODP FPAR & -14.103 & 1.25 e-103 & 21.5847 \\
\hline 5 & \multirow{2}{*}{ OLT 5 } & PASCA 2 & -14.059 & 6.13 e-103 & 21.511 \\
\cline { 3 - 6 } & & ODP FT 2 & -14.105 & $1.52 \mathrm{e}-120$ & 23.3159 \\
\hline
\end{tabular}

From the simulation with the optisystem, it is obtained the device requirements on the GPON Network of Udayana University, Sudirman Campus, as shown in table 4.

Table IV

Device requirements

\begin{tabular}{|c|c|}
\hline Nama Komponen & Jumlah \\
\hline Connector & 94 \\
\hline Transmitter & 5 \\
\hline Splitter 1x2 & 2 \\
\hline Splitter 1x4 & 3 \\
\hline Splitter 1x8 & 4 \\
\hline Splitter 1x16 & 6 \\
\hline Splitter 1x32 & 6 \\
\hline Fiber & $2.5 \mathrm{~km}$ \\
\hline Amplifier & 16 \\
\hline
\end{tabular}

\section{CONCLUSIONS}

The FTTH GPON network design of the Udayana University campus, Sudirman Campus, with 291 rooms and an assumption of $21 \mathrm{Mbps}$ for each room, then

1. The number of OLT ports required 5 pieces

2. It takes 5 core feeders and a total of $2.5 \mathrm{~km}$ of optical cable

3. Using $1 \times 2,1 \times 4,1 \times 8,1 \times 16,1 \times 32$ splitters

4. Quality of service meets ITU-T G 984.2 standards

From the research conducted, the following suggestions are as follows:

1. Because the condition of Covid-19 cannot optimally determine the amount of space, then for further research, the amount of space needs to be studied more deeply

2. The assumed bandwidth of $21 \mathrm{Mbps}$ per room needs to be studied further if it is sufficient according to the room assumption. This is because in some locations there are enormous rooms in the form of halls and very narrow rooms.

\section{REFERENCES}

[1] M. Lokhande and A. Singh, "Design and Implementation of FTTH," Int. Res. J. Eng. Technol., vol. 10, 2017.

[2] Z. Abdellaoui, Y. Dieudonne, and A. Aleya, "Design, implementation and evaluation of a Fiber To The Home (FTTH) access network based on a Giga Passive Optical Network GPON,” Array, vol. 10, 2021, doi: 10.1016/j.array.2021.100058.

[3] I. P. Yuda Pramana Putra, P. K. Sudiarta, and G. Sukadarmika, "Studi Perbandingan Jaringan Optik Eksisting dengan Gigabit Passive Optical Network (GPON) di Kampus Universitas Udayana Bukit Jimbaran,” J. SPEKTRUM, vol. 5, no. 2, 2018, doi: 10.24843/spektrum.2018.v05.i02.p06.

[4] X. Yang, "Application of GPON in Campus Network,” 2018, doi: 10.2991/hsmet-18.2018.137.

[5] K. Jiang, L. Lu, L. Pan, and K. Wang, "Construction 
and practice of all-optical campus network based on gigabit-capable passive optical networks," Shenzhen Daxue Xuebao (Ligong Ban)/Journal Shenzhen Univ. Sci. Eng., vol. 37, 2020, doi: 10.3724/SP.J.1249.2020.99184.

[6] S. Sitohang and S. A. Setiawan, "IMPLEMENTASI JARINGAN FIBER TO THE HOME (FTTH) DENGAN TEKNOLOGI GIGABIT PASSIVE OPTICAL NETWORK (GPON)," Simetris J. Tek. Mesin, Elektro dan Ilmu Komput., vol. 9, no. 2, 2018, doi: 10.24176/simet.v9i2.2430.

[7] S. Srinath, "Performance Analysis of 2.5 Gbps GPON,” 2007.

[8] L. E. Conde-Zhingre, P. A. Quezada-Sarmiento, and M. L. Labanda-Jaramillo, "Interconnection using GPON technology in an intelligent city: Case study Ciudad de Loja (Ecuador),” Espacios, vol. 39, no. 3, 2018.

[9] S. Verma, A. Kakati, Luckysaurabh, and P. Bhulania, "Performance analysis of Q-factor and polarization for GPON network using optisystem," 2017, doi: 10.1109/INCITE.2016.7857605.

[10] F. Selmanovic and E. Skaljo, "GPON in telecommunication network,” 2010, doi: 10.1109/ICUMT.2010.5676500.

[11] ITU-T G.Supplement 39, "Series G: Transmission Systems And Media, Digital Systems And Networks,” ITU-T G-series Recomm. - Suppl. 39, vol. 39, 2016. 